\title{
Identifikasi Permukiman Kumuh Berdasarkan Tingkat RT di Kelurahan Keputih Kota Surabaya
}

\author{
Elpidia Agatha Crysta dan Yanto Budisusanto \\ Departemen Teknik Geomatika, Fakultas Teknik Sipil dan Perencanaan, Institut Teknologi Sepuluh \\ Nopember (ITS) \\ e-mail: yanto_b@geodesy.its.ac.id
}

\begin{abstract}
Abstrak-Kota Surabaya sebagai pusat seluruh kegiatan Provinsi Jawa Timur merupakan kota metropolitan terbaik dan terbesar kedua di Indonesia. Namun, pertumbuhan penduduk yang terus meningkat dan tingginya arus urbanisasi yang menjadi salah satu faktor utama penyebab kepadatan penduduk yang tinggi di Surabaya. Akan tetapi, karena tekanan ekonomi dan kepadatan tempat tinggal memaksa kaum urban untuk menempati daerahdaerah pinggiran hingga membentuk lingkungan permukiman kumuh. Kelurahan Keputih sebagai studi wilayah tentunya juga tidak lepas dari permasalahan ini. Oleh karena itu, dilakukan identifikasi permukiman kumuh yang kemudian diklasifikasikan berdasarkan empat tingkat kekumuhan yakni, bukan permukiman kumuh, permukiman kumuh ringan, permukiman kumuh sedang dan permukiman kumuh berat. Dari hasil penentuan lokasi permukiman kumuh, kemudian dilakukan analisis terhadap setiap kualitas permukiman penyebab kekumuhan dengan menggunakan adanya parameter. Metode skoring digunakan penelitian ini dalam melakukan identifikasi permukiman permukiman kumuh dengan menggunakan tujuh parameter kekumuhan. Hasil penelitian menunjukkan di Kelurahan Keputih hanya menghasilkan dua klasifikasi tingkat kekumuhan, 14 RT dengan luas total permukiman 39,839 Ha termasuk dalam bukan permukiman kumuh dan 10 RT dengan luas total wilayah permukiman 21,137 Ha diklasifikasikan sebagai permukiman kumuh ringan. Sedangkan, dari hasil analisis parameter, terdapat dua parameter memiliki lokasi penyebab kekumuhan terbanyak yaitu: Kondisi Proteksi Kebakaran dan Kondisi Penyediaan Air Minum, hal ini disebabkan masih belum tersedianya sarana dan prasarana yang menunjang parameter tersebut. Hasil akhir dari penelitian ini adalah peta klasifikasi permukiman kumuh di Kelurahan Keputih.
\end{abstract}

Kata Kunci-Identifikasi Permukiman Kumuh, Kelurahan Keputih, Klasifikasi Tingkat Kekumuhan, Tingkat Kualitas Permukiman.

\section{PENDAHULUAN}

$\mathrm{K}$ OTA Surabaya memiliki kepadatan penduduk yang tinggi, fasilitas dan aksesbilitas yang lengkap dan didukung memiliki letak geografis yang strategis di Indonesia mendorong banyak penduduk melakukan urbanisasi dari berbagai daerah. Akibatnya, banyak masyarakat yang melakukan urbanisasi untuk mencari pekerjaan atau menimba ilmu sehingga tingkat kepadatan penduduk di Kota Surabaya terus meningkat setiap tahunnya.
Kebutuhan dan permintaan permukiman yang tinggi tidak didukung dengan ketersediaan lahan yang semakin terbatas. Masyarakat akhirnya mencari alternatif lain untuk memenuhi kebutuhannya dengan mendirikan permukiman di daerah pengembangan non permukiman seperti di pinggir sungai, pinggiran rel kereta api, sekitar pantai, tambak dan lain lain. Permukiman permukiman padat tersebut akhirnya berkembang menjadi permukiman permukiman tidak layak huni atau sering kita sebut sebagai permukiman kumuh [1].

Keputih, merupakan salah satu Kelurahan yang berada di Kecamatan Sukolilo dengan letak pada sisi paling Timur Kota Surabaya. Menurut Badan Pengendalian Lingkungan Hidup Kota Surabaya Tahun 2008, di Kelurahan Keputih terdapat dua titik untuk sebaran lokasi permukiman kumuh tepatnya di sekitar daerah Keputih Timur dan Keputih Tegal [2].

Dalam penelitian ini akan dilakukan identifikasi dan pemetaan permukiman kumuh serta menganalisis parameterparameter yang penyebab permukiman kumuh berdasarkan tingkat kualitas permukiman di Kelurahan Keputih. Identifikasi permukiman kumuh dilakukan berdasarkan pengertian permukiman kumuh, serta standar pelayanan minimal yang dipersyaratkan secara nasional [3] Dalam menentukan identifikasi permukiman kumuh dilakukan dengan menentukan prioritas kriteria-kriteria yang berpengaruh terhadap kekumuhan menggunakan tujuh parameter pemukiman kumuh yaitu Direktorat Pengembangan Permukiman Pemukiman, 2016.

Studi mengenai identifikasi permukiman kumuh telah dilakukan sebelumnya[4] menggunakan metode AHP (Analytical Hierarcy Process) dengan indikator permukiman kumuh bersadarkan indikator kementrian pekerjaan umum dan perumahan rakyat [5]. Hasil penelitian tersebut menampilkan 3 klasifikasi kekumuhan yaitu kekumuhan tingkat berat, sedang dan ringan. Dalam penelitian ini dilakukan identifikasi permukiman kumuh menggunakan indikator kementrian pekerjaan umum dan perumahan rakyat dengan metode skoring yang mampu menunjukkan kualitas permukiman dengan menghasilkan 4 klasifikasi tingkat kekumuhan yaitu: bukan permukiman kumuh, permukiman kumuh ringan, permukiman kumuh sedang dan permukiman kumuh berat beserta parameter-parameter penyebab kekumuhan berdasarkan tingkat kualitas permukiman.

\section{METODOLOGI PENELITIAN}




\section{A. Lokasi Penelitian}

Lokasi penelitian ini mengambil studi kasus di Kelurahan Keputih yang berada di bagian timur Kota Surabaya yang memiliki letak geografis $112^{\circ} 46^{\prime} 53^{\prime \prime}-112^{\circ} 50$ ' $48^{\prime \prime}$ BT dan $7^{\circ} 16^{\prime} 14^{\prime \prime}-7^{\circ} 18^{\prime} 36^{\prime}$ " LS. Kelurahan Keputih untuk bagian permukiman terdiri dari $4 \mathrm{RW}$ dalam $24 \mathrm{RT}$ yang memiliki luas sekitar 60,976 Ha. Dengan batas wilayah utara Kelurahan Gebang Putih dan Kecamatan Mulyorejo, barat dengan Kelurahan Klampis Ngasem, selatan dengan Kelurahan Medokan Semampir, Kelurahan Semolowaru dan Kecamatan Rungkut serta batas timur dengan Selat Madura.

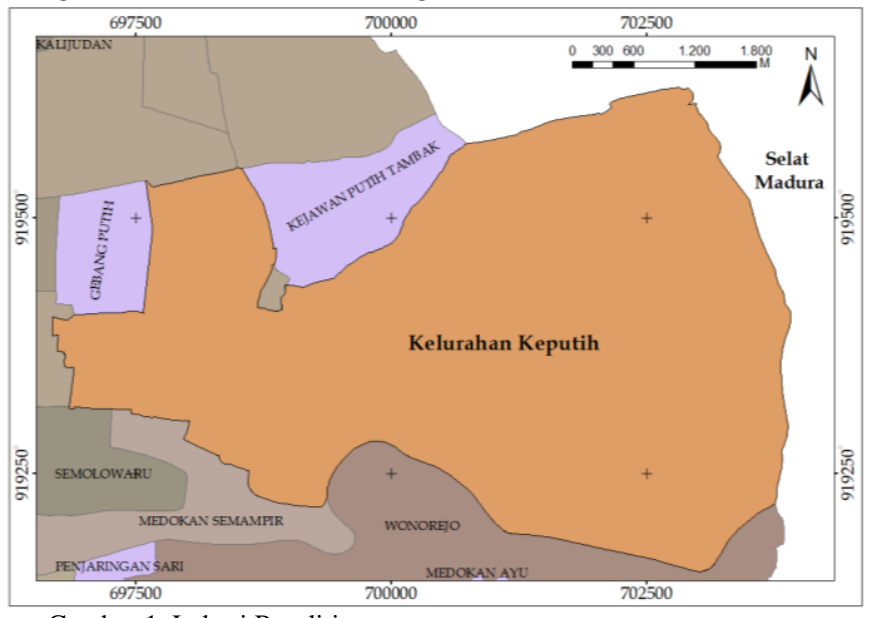

Gambar 1. Lokasi Penelitian.

\section{B. Data dan Peralatan}

1. Data

Data yang digunakan dalam penelitian ini meliputi :

a. Data primer yang dip erlukan dalam penelitian, yaitu:

- Kuisioner responden tahun 2017 mengenai program peningkatan kualitas permukiman..

b. Data sekunder yang diperlukan dalam penelitian, yaitu:

- Citra Satelit Resolusi Tinggi Pleiades 1A terektifikasi akuisisi tanggal 28 Agustus 2015.

- Peta Batas Administrasi, jaringan jalan dan jaringan sungai Kelurahan Keputih

- Batas RT di Kelurahan Keputih

2. Peralatan

Peralatan yang digunakan dalam penelitian ini meliputi perangkat lunak pengolah data dan kata, perangkat lunak pengolah angka dan perangkat lunak pengolah data spasial.

\section{Metodologi Penelitian}

Berikut adalah penjelasan tahapan-tahapan pengumpulan dan pengolahan data gambar 2, sebagai berikut :

1. Pengambilan Data

Dalam penelitian ini dibagi menjadi data peta dan data primer. Data peta yang digunakan yaitu berupa citra resolusi tinggi Pleiades $1 A$ yang telah terektifikasi, batas administrasi, batas RT, jaringan jalan, dan jaringan sungai. Kemudian dilakukan overlay untuk menghasilkan peta kerja penelitian, setelah itu dilakukan delineasi permukiman permukiman di setiap lokasi RT. Delineasi dilakukan untuk menunjukkan lokasi yang dilakukan observasi dalam penelitian. Data Primer yang diperlukan yakni, hasil survei dan wawancara kuisioner responden mengenai program peningkatan kualitas permukiman.
2. Identifikasi dan Tipologi Permukiman Kumuh

Dilakukan pemberian skor pada kriteria-kriteria berdasarkan skala penilaian yang mempengaruhi permukiman permukiman kumuh dari setiap parameter[3]. Kemudian dengan menggunakan metode skoring dilakukan analisis hingga menghasilkan klasifikasi tingkat permukiman kumuh tiap RT. Tipologi permukiman kumuh akan memberikan kategori permukiman tersebut, dimana terdiri dari permukiman kumuh di atas air, di tepi air, di dataran rendah, di perbukitan atau di daerah rawan bencana. Berikut ini merupakan kriteria-kriteria pada setiap parameter kekumuhan yang dapat dilihat pada Tabel 1.

Tabel 1.

Kriteria-Kriteria Parameter Kekumuhan

\begin{tabular}{|c|c|c|}
\hline No & Parameter & $\begin{array}{c}\text { Sub Kriteria } \\
\end{array}$ \\
\hline 1. & $\begin{array}{l}\text { Kondisi } \\
\text { Bangunan } \\
\text { Gedung }\end{array}$ & $\begin{array}{l}\text { Ketidakteraturan Bangunan } \\
\text { Tingkat Kepadatan Bangunan } \\
\text { Ketidaksesuaian Dengan Persyaratan } \\
\text { Teknis Bangunan }\end{array}$ \\
\hline 2. & $\begin{array}{l}\text { Kondisi Jalan } \\
\text { Lingkungan }\end{array}$ & $\begin{array}{l}\text { Cakupan Pelayanan Jalan Lingkungan } \\
\text { Kualitas Permukaan Jalan Lingkungan }\end{array}$ \\
\hline 3. & $\begin{array}{l}\text { Kondisi } \\
\text { Penyediaan Air } \\
\text { Minum }\end{array}$ & $\begin{array}{l}\text { Ketidaktersediaan Akses Aman Air } \\
\text { Minum } \\
\text { Tidak Terpenuhinya Kebutuhan Air } \\
\text { Minum }\end{array}$ \\
\hline 4. & $\begin{array}{l}\text { Kondisi Drainase } \\
\text { Lingkungan }\end{array}$ & $\begin{array}{l}\text { Ketidakmampuan Mengalirkan Limpasan } \\
\text { Air } \\
\text { Ketidaktersediaan Drainase } \\
\text { Ketidakterhubungan Dengan Sistem } \\
\text { Drainase } \\
\text { Tidak Terpeliharanya Drainase } \\
\text { Kualitas Konstruksi Drainase }\end{array}$ \\
\hline 5. & $\begin{array}{l}\text { Kondisi } \\
\text { Pengelolaan Air } \\
\text { Limbah }\end{array}$ & $\begin{array}{l}\text { Sistem Pengelolaan Air Limbah Tidak } \\
\text { Sesuai Standar Teknis } \\
\text { Prasarana Dan Sarana Pengelolaan Air } \\
\text { Limbah Tidak Sesuai Standar Teknis } \\
\text { Prasarana Dan Asarana Persampahan }\end{array}$ \\
\hline 6. & $\begin{array}{l}\text { Kondisi } \\
\text { Pengelolaan } \\
\text { Persampahan }\end{array}$ & $\begin{array}{l}\text { Tidak Sesuai Standar Teknis } \\
\text { Sistem Pengelolaan Persampahan Tidak } \\
\text { Sesuai Standar Teknis } \\
\text { Tidak Terpeliharanya Sarana Dan } \\
\text { Prasarana }\end{array}$ \\
\hline 7. & $\begin{array}{l}\text { Kondisi Proteksi } \\
\text { Kebakaran }\end{array}$ & $\begin{array}{l}\text { Ketidaktersediaan Prasarana Proteksi } \\
\text { Kebakaran } \\
\text { Ketidaktersediaan Sarana Proteksi } \\
\text { Kebakaran }\end{array}$ \\
\hline
\end{tabular}

Sumber: Direktorat Pengembangan Permukiman Pemukiman, 2016

Dari adanya sub krietria setiap parameter pada Tabel 1, langkah selanjutnya adalah sebagai berikut:

a. Pemberian skor setiap sub kriteria, berdasarkan parameter penilaian:

- Kualitas Parameter 0\% - 25\% : Skor 0

- Kualitas Parameter 26\% - 50\% : Skor 1

- Kualitas Parameter 51\% - 75\% : Skor 3

- Kualitas Parameter 76\% - 100\% : Skor 5

b. Perhitungan total penilaian setiap parameter didekati dengan menggunakan rumus sebagai berikut:

$\mathrm{Pi}=\frac{\sum B i}{\sum K}$

dimana:

$\mathrm{Pi}=$ Total Skor pada Setiap Parameter, Bi $=$ Skor Sub

Kriteria, K = Jumlah Sub Kriteria

c. Klasifikasi Permukiman Kumuh 
Berikut merupakan rentang nilai tingkat klasifikasi yang didapatkan untuk setiap kelas yakni:

- Bukan Permukiman Kumuh : $0-8,75$

- Permukiman Kumuh Ringan : 8,76-17,50

- Permukiman Kumuh Sedang : 17,51 - 26,25

- Permukiman Kumuh Berat : 26,26 - 35

3. Analisis Parameter Penyebab Permukiman Kumuh Dari klasifikasi berdasarkan tingkat kelas kekumuhan, selanjutnya dilakukan analisis dari hasil skoring setiap parameter pada setiap lokasi untuk mengetahui parameter dengan kualitas buruk atau sangat buruk sebagai penyebab permukiman kumuh. Klasifikasi setiap parameter didekati dengan menggunakan rentang tengah antara setiap skor dalam skala penilaian.

Berikut ini merupakan nilai klasifikasi untuk setiap tingkat kualitas parameter permukiman kumuh yakni:

- Kelas 1 (kualitas baik) $\quad: 0-0,5$

- Kelas 2 (kualitas cukup baik) : 0,51-2

- Kelas 3 (kualitas buruk) : 2,01-4

- Kelas 4 (kualitas sangat buruk): 4,01 - 5

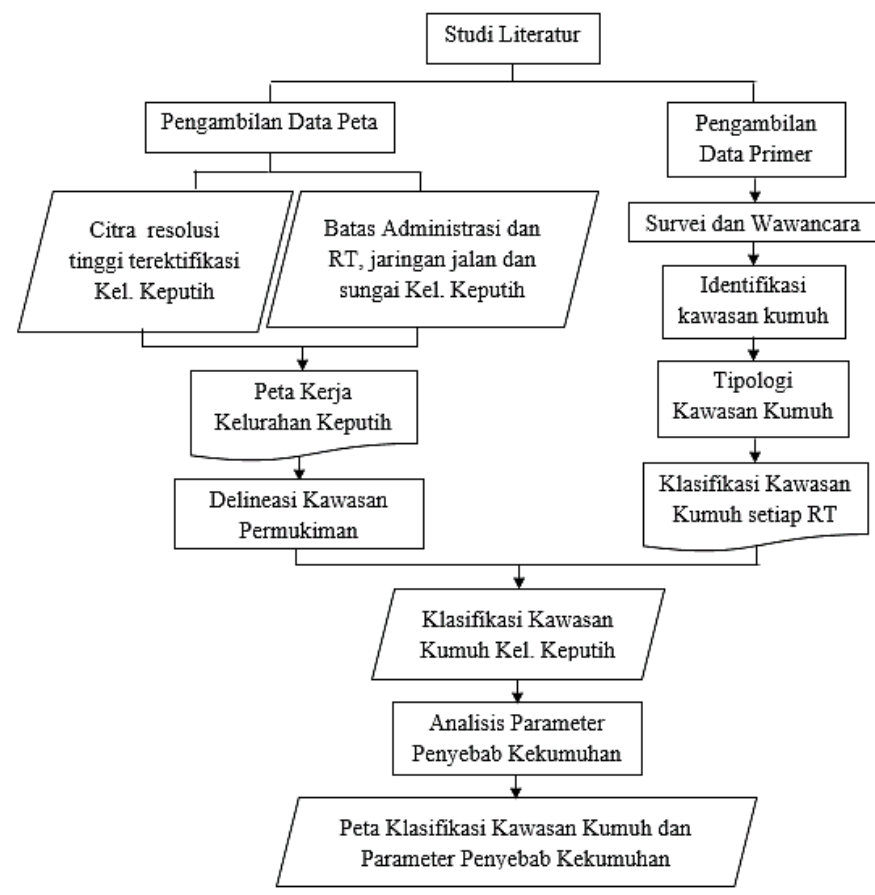

Gambar 2. Flowchart Metode Penelitian

\section{HASIL DAN PEMBAHASAN}

\section{A. Skoring Parameter-Parameter Kekumuhan}

Berikut ini merupakan hasil skoring dari setiap parameter berdasarkan hasil penilaian dari sub kriteria untuk mengetahui tingkat kualitas yang digunakan analisis parameter penyebab kekumuhan dapat dilihat pada Tabel 2, dimana setiap parameter disimbolkan dengan keterangan:

P1: Bangunan Gedung

P2: Jalan Lingkungan

P3: Penyediaan Air Minum

P5: Pengelolaan Air Limbah

P6: Pengelolaan Persampahan

P4: Drainase Lingkungan
Dari hasil Tabel 2 dapat dilihat untuk tingkat kualitas setiap parameter kekumuhan di setiap lokasi, semakin besar hasil skor yang didapatkan maka semakin buruk kualitas yang ada dan sebaliknya semakin kecil skor yang didapatkan maka kualitas semakin baik. Dari hasil skor tersebut juga dapat diketahui permasalahan penyebab kekumuhan dari setiap lokasi.

Tabel 2.

Skoring Kriteria-Kriteria Parameter Kekumuhan

\begin{tabular}{|c|c|c|c|c|c|c|c|c|}
\hline \multirow{2}{*}{$\mathbf{R W}$} & \multirow{2}{*}{ RT } & \multicolumn{7}{|c|}{ TOTAL PENILAIAN PARAMETER } \\
\hline & & P1 & $\mathbf{P 2}$ & P3 & P4 & P5 & P6 & P7 \\
\hline 01 & 01 & 0,3 & 0,5 & 0 & 0,2 & 0 & 0 & 5 \\
\hline 01 & 02 & 0,3 & 0 & 0 & 0 & 0 & 0 & 5 \\
\hline 01 & 03 & 0,3 & 0 & 0 & 0 & 0 & 2 & 5 \\
\hline 01 & 04 & 0 & 0 & 0 & 0 & 0 & 1 & 5 \\
\hline 01 & 05 & 1 & 1,5 & 0 & 0,4 & 0 & 0 & 5 \\
\hline 02 & 01 & 2 & 1,5 & 2,5 & 2,6 & 1,5 & 2 & 5 \\
\hline 02 & 02 & 0 & 0 & 0 & 0,6 & 0 & 0 & 5 \\
\hline 02 & 03 & 1 & 0 & 0 & 0 & 0 & 0 & 5 \\
\hline 02 & 04 & 0 & 0,5 & 2,5 & 0,2 & 5 & 0,7 & 5 \\
\hline 02 & 05 & 0 & 1,5 & 0 & 2,4 & 0 & 0 & 5 \\
\hline 03 & 01 & 0,3 & 0 & 0 & 0 & 0 & 1 & 5 \\
\hline 03 & 02 & 1 & 0 & 0 & 1,2 & 0 & 2 & 5 \\
\hline 03 & 03 & 1 & 0,5 & 0 & 0 & 0 & 0 & 5 \\
\hline 03 & 04 & 1 & 0 & 0 & 0 & 0 & 0 & 5 \\
\hline 03 & 05 & 0,3 & 0 & 0 & 0 & 0 & 0 & 5 \\
\hline 03 & 06 & 0,3 & 0 & 0 & 0 & 0 & 0 & 5 \\
\hline 08 & 01 & 1 & 0,5 & 0 & 0 & 0 & 0 & 5 \\
\hline 08 & 02 & 2,7 & 0 & 0 & 0,4 & 2 & 2 & 5 \\
\hline 08 & 03 & 1,7 & 0 & 2,5 & 0 & 0 & 0 & 5 \\
\hline 08 & 04 & 2 & 2,5 & 2,5 & 0,6 & 1,5 & 1 & 5 \\
\hline 08 & 05 & 1 & 0 & 0 & 0 & 0 & 0 & 5 \\
\hline 08 & 06 & 0 & 0 & 2,5 & 1 & 1,5 & 3,3 & 5 \\
\hline 08 & 07 & 1,7 & 2 & 2,5 & 2 & 0,5 & 1,7 & 5 \\
\hline 08 & 08 & 0 & 0 & 2,5 & 0,6 & 3 & 1,7 & 5 \\
\hline
\end{tabular}

Sumber: Hasil Analisis, 2017

\section{B. Klasifikasi dan Tipologi Permukiman Kumuh}

Dari hasil pengolahan menggunakan metode skoring setiap parameter, kemudian dijumlahkan untuk mendapatkan tingkat kekumuhan yang kemudian dibagi berdasarkan empat klasifikasi. Berikut ini hasil tingkat kekumuhan beserta tipologi permukiman kumuh berdasarkan hasil survei dan orientasi lapangan yang dapat dilihat pada Tabel 3.

Tabel 3.

Klasifikasi Tingkat Kekumuhan

\begin{tabular}{ccccc}
\hline \hline RW & RT & Total Nilai & $\begin{array}{c}\text { Tingkat } \\
\text { Klasifikasi }\end{array}$ & Luas (Ha) \\
\hline 01 & 01 & 6 & Bukan Kumuh & 2,157 \\
01 & 02 & 5,3 & Bukan Kumuh & 2,245 \\
01 & 03 & 7,3 & Bukan Kumuh & 2,077 \\
01 & 04 & 6 & Bukan Kumuh & 1,011 \\
01 & 05 & 7,9 & Bukan Kumuh & 3,947 \\
02 & 01 & 17,1 & Kumuh Ringan & 1,354 \\
02 & 02 & 5,6 & Bukan Kumuh & 1,424 \\
02 & 03 & 6 & Bukan Kumuh & 6,421 \\
02 & 04 & 13,9 & Kumuh Ringan & 1,742 \\
02 & 05 & 8,9 & Kumuh Ringan & 2,119 \\
03 & 01 & 6,3 & Bukan Kumuh & 0,952 \\
03 & 02 & 9,2 & Kumuh Ringan & 3,174 \\
03 & 03 & 6,5 & Bukan Kumuh & 3,064 \\
03 & 04 & 6 & Bukan Kumuh & 2,301 \\
03 & 05 & 5,3 & Bukan Kumuh & 1,458 \\
03 & 06 & 5,3 & Bukan Kumuh & 3,546 \\
08 & 01 & 6,5 & Bukan Kumuh & 5,429 \\
08 & 02 & 12,1 & Kumuh Ringan & 7,084 \\
08 & 03 & 9,2 & Kumuh Ringan & 0,584 \\
08 & 04 & 15,1 & Kumuh Ringan & 2,219 \\
08 & 05 & 6 & Bukan Kumuh & 3,807 \\
\hline
\end{tabular}




\begin{tabular}{lllll}
08 & 06 & 13,3 & Kumuh Ringan & 0,737 \\
08 & 07 & 15,4 & Kumuh Ringan & 1,110 \\
08 & 08 & 12,8 & Kumuh Ringan & 1,014 \\
\hline \hline
\end{tabular}

Sumber: Hasil Analisis, 2017.

Dari hasil klasifikasi diperoleh hasil yaitu, 10 lokasi di Kelurahan Keputih teridentifikasi permukiman kumuh ringan dengan luas total wilayah permukiman $21,137 \mathrm{Ha}$ dan 14 lokasi sisanya terindikasi bukan permukiman kumuh dengan luas total permukiman 39,839 $\mathrm{Ha}$, dengan kondisi tipologi permukiman kumuh, yaitu:

1. Kumuh di dataran rendah dan tepi air: RW 01 RT 02, RW 08 terdiri dari RT 03, RT 04, RT 06 dan RT 08.

2. Kumuh di tepi air: RW 02 RT 04 dan RW 08 RT 07.

3. Kumuh di daerah rawan banjir: RW 02 RT 05.

4. Kumuh di dataran rendah: RW 03 RT 02 dan RW 08 RT 02.

\section{Analisis Parameter Penyebab Kekumuhan}

Dengan menggunakan hasil klasifikasi tingkat permukiman kumuh maka diperoleh lokasi-lokasi permukiman kumuh, dimana dari hasil dapat dianalisis parameter-parameter penyebab permukiman kumuh di setiap lokasi dengan melihat tingkat kualitas parameter di permukiman permukiman kumuh. Pada tabel 4 dapat dilihat dari setiap lokasi terhadap parameter penyebab kekumuhan.

Tabel 4.

Parameter Penyebab Permukiman Kumuh

\begin{tabular}{|c|c|c|}
\hline RW & RT & Parameter Penyebab Kekumuhan \\
\hline 01 & 01 & Proteksi Kebakaran \\
\hline 01 & 02 & Proteksi Kebakaran \\
\hline 01 & 03 & Proteksi Kebakaran \\
\hline 01 & 04 & Proteksi Kebakaran \\
\hline 01 & 05 & Proteksi Kebakaran \\
\hline 02 & 01 & $\begin{array}{c}\text { Penyediaan Air Minum, Drainase Lingkungan dan } \\
\text { Proteksi Kebakaran }\end{array}$ \\
\hline 02 & 02 & Proteksi Kebakaran \\
\hline 02 & 03 & Proteksi Kebakaran \\
\hline 02 & 04 & $\begin{array}{c}\text { Penyediaan Air Minum, Pengelolaan Air Limbah dan } \\
\text { Proteksi Kebakaran }\end{array}$ \\
\hline 02 & 05 & Drainase Lingkungan dan Proteksi Kebakaran \\
\hline 03 & 01 & Proteksi Kebakaran \\
\hline 03 & 02 & Proteksi Kebakaran \\
\hline 03 & 03 & Proteksi Kebakaran \\
\hline 03 & 04 & Proteksi Kebakaran \\
\hline 03 & 05 & Proteksi Kebakaran \\
\hline 03 & 06 & Proteksi Kebakaran \\
\hline 08 & 01 & Proteksi Kebakaran \\
\hline 08 & 02 & Kondisi Bangunan dan Proteksi Kebakaran \\
\hline 08 & 03 & Penyediaan Air Minum dan Proteksi Kebakaran \\
\hline 08 & 04 & $\begin{array}{l}\text { Jalan Lingkungan, Penyediaan Air Minum dan Proteksi } \\
\text { Kebakaran }\end{array}$ \\
\hline 08 & 05 & Proteksi Kebakaran \\
\hline 08 & 06 & $\begin{array}{c}\text { Penyediaan Air Minum, Pengelolaan Persampahan dan } \\
\text { Proteksi Kebakaran }\end{array}$ \\
\hline 08 & 07 & Penyediaan Air Minum dan Proteksi Kebakaran \\
\hline 08 & 08 & $\begin{array}{c}\text { Penyediaan Air Minum, Pengelolaan Air Limbah dan } \\
\text { Proteksi Kebakaran }\end{array}$ \\
\hline
\end{tabular}

Sumber: Hasil Analisis, 2017

Uraian berikut merupakan penjelasan Tabel 4 analisis yang diperoleh, yaitu:

1. Kualitas bangunan gedung: hanya di lokasi RW 08 RT 02 yang teridentifikasi memiliki kualitas buruk, karena pada lokasi ini terdapat rumah-rumah tidak permanen yang terbangun dengan kondisi yang tidak memenuhi standar dilihat dari sisi kenyamanan, keamanan, kesehatan dan lain sebagainya di sekitar TPS di Kelurahan Keputih.

2. Kualitas jalan lingkungan: hanya di lokasi RW 08 RT 04 yang teridentifikasi memiliki kualitas buruk, hal ini disebabkan pada lokasi ini mengalami perluasan wilayah dimana sebagian permukaan jalan belum terstruktur dan sebagian besar mengalami kerusakan.

3. Kualitas penyediaan air minum: di lokasi RW 02 terdiri dari RT 01 dan RT 04, RW 08 terdiri dari RT 03, RT 04, RT 06, RT 07 dan RT 08 yang teridentifikasi memiliki kualitas buruk, hal ini disebabkan tidak adanya jaringan perpipaan untuk memenuhi kebutuhan air minum setiap individu dikarenakan status lahan yang ditidak dapat dibangun saluran PDAM.

4. Kualitas drainase lingkungan: di lokasi RW 02 terdiri dari RT 01 dan RT 05 yang teridentifikasi memiliki kualitas buruk. Untuk RT 01 hal ini disebabkan hampir seluruh lokasi tidak memiliki drainase. Sedangkan RT 05 sebagian wilayah pada lokasi ini tidak memiliki drainase sehingga putusnya keterhubungan dengan sistem drainase lainnya yang mengakibatkan genangan cukup tinggi ketika intensitas hujan yang cukup lama, disebabkan ketidakmampuan drainase mengalirkan limpasan air hujan.

5. Kualitas pengelolaan air limbah: di lokasi RW 02 RT 04 terindikasi sangat buruk hal ini karena sebagian besar belum memiliki tangki septik baik secara individu maupun komunal sebagai penampungan limbah dan RW 08 RT 08 teridentifikasi memiliki kualitas buruk karena sebagian belum memiliki tangki septik sebagai penampungan limbah dan kondisi beberapa MCK maupun MCK umum yang kurang memenuhi standar.

6. Kualitas pengelolaan persampahan: hanya di lokasi RW 08 RT 06 yang teridentifikasi memiliki kualitas buruk, hal ini disebabkan sebagian besar tidak adanya pewadahan untuk penampungan (bak) sampah rumah tangga dan tidak terpeliharanya sarana dan prasarana persampahan.

7. Kualitas proteksi kebakaran: semua lokasi terindikasi memiliki kualitas sangat buruk, hal ini dikarenakan di setiap RT Kelurahan Keputih belum memiliki sarana maupun prasarana proteksi kebakaran dimana semua lokasi masih bergantung pada skala kelurahan.

\section{KESIMPULAN}

Berdasarkan hasil identifikasi permukiman kumuh berdasarkan kualitas permukiman maka di dapatkan beberapa kesimpulan sebagai berikut:

1. Dari hasil pemetaan yang kemudian dilakukan klasifikasi tingkat kekumuhan hanya dihasilkan dua tingkat kekumuhan yaitu, 14 RT dengan luas total permukiman 39,839 Ha termasuk dalam bukan permukiman kumuh dan $10 \mathrm{RT}$ dengan luas total wilayah permukiman 21,137 $\mathrm{Ha}$ termasuk dalam permukiman kumuh ringan. Berikut merupakan lokasi yang merupakan permukiman kumuh ringan:

- RW 02 terdiri dari RT 01, RT 04 dan RT 05.

- RW 03 RT 02.

- RW 08 terdiri dari RT 02, RT 03, RT 04, RT 06, RT 07 dan RT 08. 
2. Dari hasil penetapan lokasi permukiman kumuh, didapatkan analisis parameter-parameter yang menyebabkan permukiman kumuh adalah:

a. Kondisi bangunan: RW 08 RT 02.

b. Kondisi jalan lingkungan: RW 08 RT 04.

c. Kondisi penyediaan air minum:

- RW 02 terdiri dari RT 01 dan RT 04

- RW 08 terdiri dari RT 03, RT 04, RT 06, RT 07 dan RT 08

d. Kondisi drainase lingkungan: RW 02 terdiri dari RT 01 dan RT 05.

e. Kondisi pengelolaan air limbah: RW 02 RT 04 dan RW 08 RT 08.

f. Kondisi pengelolaan persampahan: RW 08 RT 06

g. Kondisi proteksi kebakaran: semua lokasi

Kondisi proteksi kebakaran dan kondisi penyediaan air minum merupakan parameter penyebab dengan lokasi permukiman kumuh terbanyak, ini dikarenakan semua lokasi RT di Kelurahan Keputih belum memiliki pengaman kebakaran dan tujuh lokasi RT belum memiliki saluran perpipaan yang dapat digunakan untuk air minum dengan kapasitas yang mencukupi.

\section{DAFTAR PUSTAKA}

[1] E. Budiharjo, Tata Ruang Perkotaan. Bandung: Alumni, 1997.

[2] D. P. U. C. K. K. Surabaya, Dokumen Strategi Pengembangan Permukiman dan Insfrastruktur Perkotaan Kota Surabaya. Surabaya: Kementrian Pekerjaan Umum dan Perumahan Rakyat., 2010.

[3] D. P. P. Pemukiman, Panduan Penyusunan Rencana Pencegahan dan Peningkatan Kualitas Permukiman Kumuh Perkotaan (RP2KPKP). Jakarta: Direktorat Jenderal Cipta Karya Kementerian Pekerjaan Umum dan Perumahan Rakyat, 2016.

[4] D. P. P. Pemukiman, Panduan Pendampingan Penyusunan Raperda tentang Pencegahan dan Peningkatan Kualitas Perumahan Kumuh dan Permukiman Kumuh. Jakarta: Direktorat Jenderal Cipta Karya Kementerian Pekerjaan Umum dan Perumahan Rakyat, 2016.

[5] H. F. Ilmy, "Identifikasi Permukiman Permukiman Kumuh Menggunakan Metode AHP (Analytical Hierarcy Process) (Studi Kasus: Kecamatan Klojen, Kota Malang)," Institut Teknologi Sepuluh Nopember, 2016. 